\title{
Stable wastewater treatment with Neochloris oleoabundans in a tubular photobioreactor
}

\author{
Dimitar Valev ${ }^{1} \cdot$ Hellen Silva Santos ${ }^{2} \cdot$ Esa Tyystjärvi ${ }^{1}$ (D)
}

Received: 3 April 2019 /Revised and accepted: 31 July 2019/Published online: 22 August 2019

(C) The Author(s) 2019

\begin{abstract}
The potential of a wastewater treatment and biomass production process with the green microalgae Neochloris oleoabundans in a 45-L tubular photobioreactor was tested. In a stable and reliable alga-based process, wastewaters should undergo pre-treatment to remove colored substances. Our data show that further optimization steps may be required, such as adjustment of the N:P ratio and addition of essential metals. As a final result, parameters were established for a continuous-mode photobioreactor run with optimized wastewater for five times the hydraulic retention time $(157 \mathrm{~h})$ at the dry biomass concentration of $0.47 \pm 0.03 \mathrm{~g} \mathrm{~L}^{-1}$. During that period, $75 \%$ and $99.6 \%$ removal efficiencies for $\mathrm{NH}_{4}{ }^{+}$and $\mathrm{PO}_{4}{ }^{3-}$, respectively, were achieved.
\end{abstract}

Keywords Wastewater treatment $\cdot$ Microalgae $\cdot$ Chlorophyta $\cdot$ Tubular photobioreactor $\cdot$ Batch process $\cdot$ Turbidostat process $\cdot$ Heavy metals

\section{Introduction}

In the past decade, microalga-based systems have gained interest as alternatives for wastewater treatment (Selvaratnam et al. 2015). Microalgae can be grown using wastewaters as growth media since wastewaters are rich in nutrients such as ammonium $\left(\mathrm{NH}_{4}{ }^{+}\right)$, nitrate $\left(\mathrm{NO}_{3}{ }^{-}\right)$, and phosphate $\left(\mathrm{PO}_{4}{ }^{3-}\right)$. Microalgae take up and utilize these compounds efficiently, incorporating them into their biomass (Shen et al. 2017). Furthermore, microalgae are a potential renewable source for a variety of valuable compounds with a broad range of commercial applications (Pulz and Gross 2004; Spolaore et al. 2006). Implementation of microalgae for wastewater treatment might be combined with production of valuable compounds as by-products to improve the economical sustainability of the system (Kligerman and Bouwer 2015).

Wastewaters have different origins from municipal to complex industrial wastewaters. However, most of them come with

Electronic supplementary material The online version of this article (https://doi.org/10.1007/s10811-019-01890-x) contains supplementary material, which is available to authorized users.

Esa Tyystjärvi

esatyy@utu.fi

1 Department of Biochemistry/Molecular Plant Biology, University of Turku, 20014 Turku, Finland

2 Department of Chemistry, University of Turku, 20014 Turku, Finland high chemical oxygen demand (COD) and/or biological oxygen demand (BOD), indicating organic constituents, and with high total suspended solids (TSS) that cause turbidity. Although many microalgae can grow mixotrophically, microalgae are generally not efficient in removing organic compounds from the wastewater, when compared with the conventional activated sludge process (Wang et al. 2010). Therefore, wastewaters with a low BOD are expected to be suitable for microalgal wastewater treatment. Wastewaters coming after anaerobic processes such as landfill leachate, an anaerobic digester, or secondary aerobic treatment (activated sludge) are characterized with low BOD. However, these wastewaters usually still contain a relatively high amount of bacterial biomass and non-degradable organic compounds (part of COD) and are highly turbid due to suspended solids. Bacterial biomass has to be removed before the wastewater enters the photobioreactor (PBR), since bacteria easily can overtake the microalgal culture or lower its vitality (de la Noüe et al. 1994; Huntley and Redalje 2007; Zhang et al. 2012). Furthermore, turbidity limits the light path in the PBR, lowering the photosynthetic photon flux density (PPFD) for microalgal photosynthesis, which slows down biomass production. Therefore, a series of filtering procedures needs to be implemented in the design of a microalgal process to remove particulate matter from the wastewater. Any form of pre-treatment will result in changes of the wastewater parameters and nutrient content. Coagulation-flocculation, adsorption, and membrane filtration are efficient ways to remove organic matter from wastewaters and suspended solids. However, those methods may also filter out essential 
micronutrients. In order to establish a fast and reliable process with microalgae and wastewaters, the algae need several metals and other micronutrients at certain concentration ratios. Several heavy metals, including iron, copper, molybdenum, zinc, cobalt, and manganese, play important roles in algal physiology as enzyme co-factors and activators, especially in reactions involving electron transfer and photosynthesis (Barber 2003; Hänsch and Mendel 2009). As micronutrients are needed in low concentrations, it is usually assumed that wastewaters contain enough of these substances and therefore most of the research done in the wastewater field has been focused on the macronutrients. In fact, most studies on heavy metals focus on contaminations in natural fresh water reservoirs and oceans (Mehta and Gaur 2005; Fu and Wang 2011). However, municipal wastewaters may have relatively low concentrations of metals (Karvelas et al. 2003; Chirila et al. 2014) and only experiments with actual wastewaters can show if the concentrations of metals are high enough for continuous algal growth.

In order to achieve production of a valuable compound in high amounts and purity, the process mainly has to utilize the features of single algal species that can produce the compound of interest. At industrial conditions, an axenic culture is hard to achieve. However, the impact of contamination and the number of non-desirable microbial species can be reduced via maintaining optimal growth conditions for the strain of interest. Therefore, closed systems such as tubular or flat panel photobioreactors are usually the preferred choice of growth system. Furthermore, in order to obtain maximum biomass productivity, macronutrients must be maintained at optimal concentrations. As a general guideline the Redfield ratio (Redfield 1934) has been adopted as a rule of thumb for predicting whether nitrogen or phosphorus limits primary productivity in a particular environment. However, when establishing a process around one microalgal species, it is crucial to operate at an N/P ratio that is optimal for the species of choice. As the optimal N/P ratio is species specific and wastewaters are extremely diverse, a microalgal species of commercial interest might not be the best choice for direct use in a particular wastewater, as the N/P ratio of the wastewater might not be optimal for it.

In the present study, we grew the fresh water alga Neochloris oleoabundans (Chlorophyta), in wastewaters in a 45-L tubular PBR. This green alga is known to accumulate up to $40 \%$ of lipids in its biomass, a significant part of which are triacylglycerols, making it a suitable candidate for biodiesel production ( $\mathrm{Li}$ et al. 2008). Our research has shown that in order to establish a reliable and stable continuous process with $N$. oleoabundans and wastewaters, the heavy metal content and the N/P molar ratio need to be adjusted according to the requirements of the algal species .

\section{Materials and methods}

\section{Microalgae}

Neochloris oleoabundans 1185 was from UTEX (Texas, USA). The microalgae were cultured and maintained as 30 - $\mathrm{mL}$ cultures (in $100 \mathrm{~mL}$ flasks) in BG11 medium (Rippka et al. 1979) at $20^{\circ} \mathrm{C}$, photon flux density (PPFD) $30 \mu \mathrm{mol}$ photons $\mathrm{m}^{-2} \mathrm{~s}^{-1}$ and atmospheric $\mathrm{CO}_{2}$. Inocula for the upscale experiments were prepared in a 5 -L flask, starting with three $30-\mathrm{mL}$ cultures in a volume of $2 \mathrm{~L}$, at $25^{\circ} \mathrm{C}$, PPFD $150 \mu \mathrm{mol}$ photons $\mathrm{m}^{-2} \mathrm{~s}^{-1}$ and $1 \% \mathrm{CO}_{2}$.

\section{Photobioreactor design and features}

An upscale vertical tubular PBR was constructed from scratch (Fig. 1). The reactor consists of transparent acrylic tubes (PLEXIGLAS-XT, Evonik Röhm GmbH, Germany) with inner and outer diameters of 40 and $50 \mathrm{~mm}$. Each tube is $2 \mathrm{~m}$ long and was bent at the end in U-turn shape. The tubes are stacked vertically and connected via pipe union fittings (ABS, GFPS, Switzerland) in a helix-like structure, closing the loop with a degasser unit. The degasser unit was constructed from high-impact-grade clear acrylic with $6 \mathrm{~mm}$ wall thickness. The degasser is used as an inlet point for the growth medium and temperature sensor and as an outlet for the harvest and air. The vertical construction of the reactor with tube modules enables easy adjustment of the working volume (40 to $100 \mathrm{~L}$ ) by adding or removing tubes. The footprint of the reactor is $2 \mathrm{~m}$ by $0.5 \mathrm{~m}$. The reactor operates as an airlift in which circulation and degassing are achieved with one air pump (LA-28B, Nitto Kohki, Japan).

The reactor is equipped with seven in-line, real-time sensors including a pH meter (Signet 2726DryLoc Electrode, GFPS, Switzerland), a flow meter (2537 Flow Sensor, GFPS, Switzerland), an optical density sensor at $880 \mathrm{~nm}$ (home-made turbidity sensor, described below), an optical density sensor at $680 \mathrm{~nm}$ (home-made OD680 sensor, described below), two optical oxygen sensors spots (OXSP5, PyroScience, Germany), and a submersible temperature sensor (TSUB21, PyroScience, Germany). All sensors are connected to NI DAQ device (NI USB-6218, National Instruments, USA), acting as a main controller unit.

The $\mathrm{pH}$ electrode is equipped with Smart sensor Electronics (2751-2, GFPS, Switzerland). The flow and $\mathrm{pH}$ sensors are incorporated in the last bottom tube via T-shaped fittings (ABS 310, GFPS, Switzerland). Both sensors are connected to the NI DAQ controller using analog output protocols, following the manufacturers' instructions.

The 880 and $680 \mathrm{~nm}$ OD sensors consist of a $5 \mathrm{~mm}$ LED, emitting at $880 \mathrm{~nm}$ (SFH 484-2, Osram Opto, Germany) or 680 nm (L680-06 AU, Epitex, Japan), respectively, and corresponding photodiodes (SFH 203 PFA and SFH 203 P, 


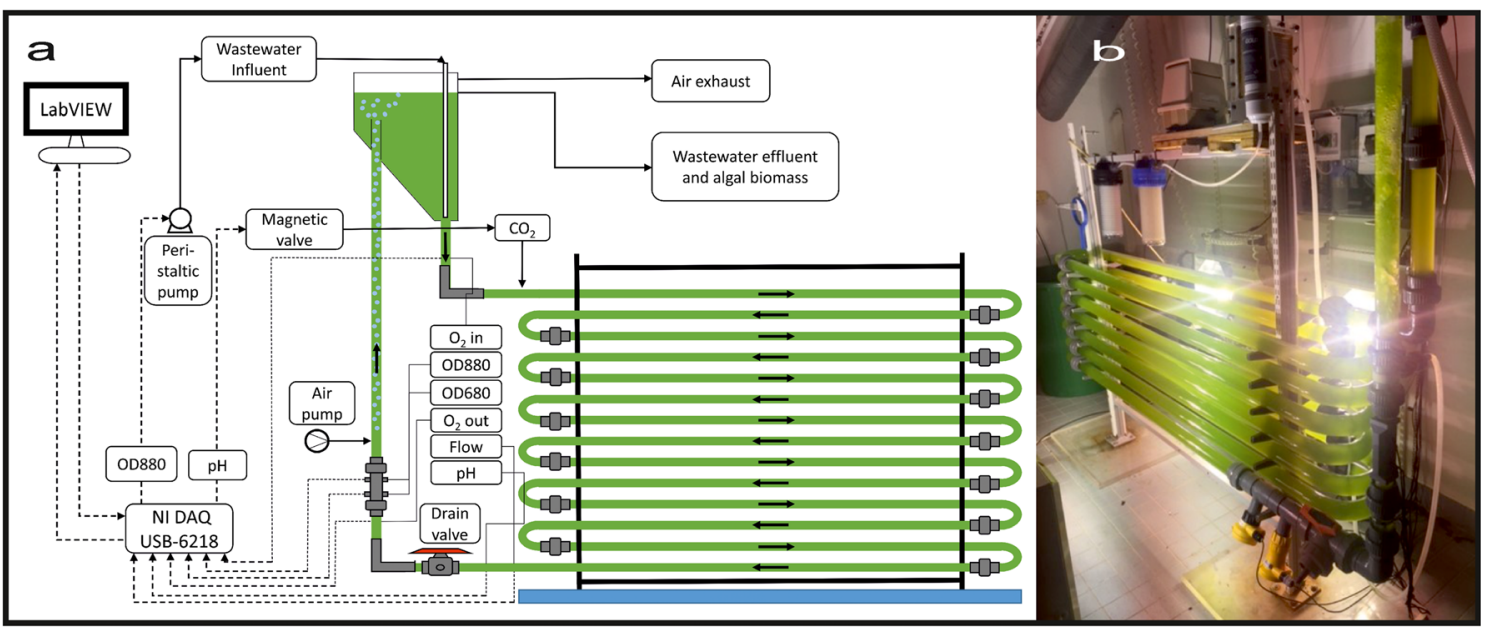

Fig. 1 Upscale tubular photobioreactor experimental set up. a Schematics. b The system under operation with N. oleoabundans

respectively, both from Osram Opto, Germany). The electrical drawings can be seen in Figure S1. A custom stainless steel part was designed and constructed to integrate the optical sensors into the reactor. The turbidity sensor $\left(\mathrm{OD}_{880}\right)$ gives indirectly the biomass concentration, enabling turbidostat operation of the reactor. $\mathrm{OD}_{680}$ shows the relative chlorophyll content.

The oxygen sensors were placed before and after the degassing unit, which allowed oxygen production to be observed during an experiment. The temperature sensor was inserted in the degasser. The oxygen and temperature sensors were connected to a FireStingO2 oxygen meter (PyroScience, Germany). The connection with the main controller device was done via analog outputs of the FireStingO2 meter, which was first calibrated using the Oxygen Logger Software (PyroScience, Germany).

Control software was designed with NI LabView (National Instruments, USA). The software provides real-time graphical display of all the measured parameters with a $10 \mathrm{~s}$ sampling rate for all sensors. The readings from the sensors are saved as a file that later can be opened with Microsoft Excel for data analysis.

\section{Experimental set up and process operation}

In every experiment, batch operational mode was the first step of the run. During each batch mode, the turbidity sensor was calibrated by once-per-day sampling for dry weight biomass measurements. This allowed continuous turbidostat operation by setting a constant $\mathrm{OD}_{880}$ value corresponding to the biomass concentration of choice. The turbidostat was enabled by a peristaltic pump (323, Watson Marlow, USA), connected to the NI DAQ device, diluting the working reactor volume with fresh growth medium every time $\mathrm{OD}_{880}$ exceeded a set threshold value.

Constant reactor volume was ensured via overflow protrusion in the degasser, which also acted as an air outlet. The harvest leaving through the overflow was collected in a 200 -
L tank and the amount of harvest was measured with a weight balance (GFK 150H, Adam DU, UK), operated by utility software (Adam DU, UK). This allowed growth rate determination of the culture as well as estimation of system productivity.

Constant $\mathrm{pH}$ of 7.5, set in the software, was achieved by addition of $99 \% \mathrm{CO}_{2}$ via a magnetic valve plugged into a relay connected to the NI DAQ device. This single $\mathrm{pH}$ threshold was applied for opening and closing the valve.

Three $400 \mathrm{~W}$ multimetal halide (HQI) lamps were used as artificial light sources. Two lamps were placed at the backside of the reactor and one up front. The distance between the lamps and reactor was adjusted by using a PPFD meter (LI250A, LI-COR, USA) so that the direct PPFD at the surface of the tubes never exceeded $300 \mu \mathrm{mol}$ photons $\mathrm{m}^{-2} \mathrm{~s}^{-1}$. Tube velocity was set to $0.21 \mathrm{~m} \mathrm{~s}^{-1}$ by adjusting the height of the degasser.

The PBR was operated in an air-conditioned room, and no additional temperature control was integrated in the system. However, during summer times, three conventional air blowers were used to maintain the temperature below $30^{\circ} \mathrm{C}$.

\section{Origin and pre-treatment of wastewater}

Helsinki Region Environmental Services Authority (HSY), managing municipal wastes in Helsinki area, Finland, provided the wastewater used in this study. After collection, the wastewater was stored at $4{ }^{\circ} \mathrm{C}$ in closed barrels for 2 weeks before the experiment. The company's label for the wastewater stream is KA2, and it is groundwater which is contaminated with leachate seeping through the bottom structures of an anaerobic landfill. The wastewater was analyzed by a commercial service (Eurofins Environment Testing Finland on November 9, 2017; Table 1).

Prior to the experiments, the wastewater was filtered through a Granular Activated Carbon (GAC) unit and a 
Table 1 Analysis of KA2 wastewater provided by HSY

\begin{tabular}{lrl}
\hline $\mathrm{pH}$ & \multicolumn{1}{l}{7.4} & \\
\hline Conductivity & 2000 & $\mathrm{\mu S} \mathrm{cm}^{-1}$ \\
BOD 7-ATU & 11 & $\mathrm{mgO}_{2} \mathrm{~L}^{-1}$ \\
CODCr & 220 & $\mathrm{mgO}_{2} \mathrm{~L}^{-1}$ \\
Chloride (Cl) & 190 & $\mathrm{mg} \mathrm{L}^{-1}$ \\
Sulfate & 25 & $\mathrm{mg} \mathrm{L}^{-1}$ \\
Total nitrogen & 95 & $\mathrm{mg} \mathrm{L}^{-1}$ \\
Ammonium & 92 & $\mathrm{mg} \mathrm{L}^{-1}$ \\
\hline
\end{tabular}

$0.1 \mu \mathrm{m}$ polyvinylidene fluoride (PVDF) membrane filter (Polymem, Waterpia GOLD, South Korea). The GAC unit was self-made from a 20 -L canister filled half way with GAC (Jacobi Carbons AB, Sweden). Wastewater was pumped in up-flow manner at $50 \mathrm{~mL} \mathrm{~min}^{-1}$.

\section{Nutrient analysis}

Nutrient analysis was by spectrophotometric methods, using a Genesys 10S UV-VIS (Thermo Fisher Scientific, USA) spectrophotometer. The ammonium test was calibrated against standard solutions of $\mathrm{NH}_{4} \mathrm{Cl}$ ( $\geq 99.8 \%$, Merck, Germany), for a dynamic range of 0 to $50.3540 \mathrm{mg} \mathrm{L}^{-1}$ (0 to $2.79 \times$ $10^{-3} \mathrm{~mol} \mathrm{~L}^{-1}$ ), presenting a calibration sensitivity of $0.016 \pm$ $0.001 \mathrm{mg} \mathrm{L}^{-1}$ (Fig. S2). The nitrate test was calibrated with standard solutions of $\mathrm{NaNO}_{3}(\geq 99.99 \%$, Merck) for a dynamic range of 0 to $50.9843 \mathrm{mg} \mathrm{L}^{-1}\left(0\right.$ to $\left.8.22 \times 10^{-4} \mathrm{~mol} \mathrm{~L}^{-1}\right)$ and a calibration sensitivity of $0.0206 \pm 0.001 \mathrm{mg} \mathrm{L}^{-1}$ (Fig. S3). The phosphate test was calibrated against standard solutions of $\mathrm{KH}_{2} \mathrm{PO}_{4}(\geq 99.995 \%$, Merck), for a dynamic range of 0 to $4.0403 \mathrm{mg} \mathrm{L}^{-1}$ (0 to $4.25 \times 10^{-5} \mathrm{~mol} \mathrm{~L}^{-1}$ ), presenting a calibration sensitivity of $0.162 \pm 0.002 \mathrm{mg} \mathrm{L}^{-1}$ (Fig. S4). The sulfate test was calibrated with standard solutions of $\mathrm{K}_{2} \mathrm{SO}_{4}$ ( $\geq 99.999 \%$, Merck), for a dynamic range of 0 to $59.7351 \mathrm{mg} \mathrm{L}^{-1}$ ( 0 to $6.22 \times 10^{-4} \mathrm{~mol} \mathrm{~L}^{-1}$ ), having a calibration sensitivity of $0.010 \pm 0.001 \mathrm{mg} \mathrm{L}^{-1}$ (Fig. S5).

The nutrient measurements of PBR samples were done after filtering through a $0.2-\mu \mathrm{m}$ filter (Whatman, Germany). Samples with concentrations greater than the dynamic range of the method were diluted accordingly.

\section{Biomass dry weight analysis}

Triplicate samples for dry weight analysis were collected daily. Sample volumes of $5 \mathrm{~mL}$, diluted to a total volume of $10 \mathrm{~mL}$ with $0.5 \mathrm{M}$ ammonium formate, were filtered over pre-weighed glass fiber-filters (VWR, USA), and followed by re-washing with $40 \mathrm{~mL}$ of $0.5 \mathrm{M}$ ammonium formate. The filtered biomass was dried overnight in $96{ }^{\circ} \mathrm{C}$ oven. Prior to weighing with an analytical balance (MC1 RC 210$\mathrm{P}$, Sartorius, Germany), the filters were cooled down for $1 \mathrm{~h}$ in a desiccator at room temperature.

\section{Quantum yield measurements}

The ratio of variable to maximum fluorescence $\left(\mathrm{F}_{\mathrm{V}} / \mathrm{F}_{\mathrm{M}}\right)$, estimating the maximum quantum yield of Photosystem II (PSII) electron transfer, was measured from samples taken from the reactor, using a pulse amplitude modulation fluorometer (AquaPen 100, PS Instruments, Czech Republic). Each sample was dark incubated for $10 \mathrm{~min}$ prior to the measurement. The $\mathrm{F}_{0}$ fluorescence was first measured with the weak measuring beam of the fluorometer, and then PSII reaction centers were closed with a saturating light pulse to obtain $\mathrm{F}_{\mathrm{M}}$.

\section{Nutrient removal efficiency and biomass yield on ammonium}

$\mathrm{NH}_{4}{ }^{+}$and $\mathrm{PO}_{4}{ }^{3-}$ removal efficiencies were calculated by the formula

$\mathrm{NRE}=\frac{\text { Concentration }(\text { influent })-\text { Concentration }(\text { effluent })}{\text { Concentration(influent })} \times 100$,

where NRE is the nutrient removal efficiency (\%).

\section{Results}

\section{Wastewater pre-treatment}

The KA2 wastewater has characteristics of leachate from an old landfill, with a BOD/COD ratio of 0.055 (Table 1) (Renou et al. 2008). Even though the pH, according to the measurements done regularly by HSY, is listed to be 7.4, our measurements indicated $\mathrm{pH} 8.2$, indicating that anaerobic processes occurred in the transportation and storage barrels. The KA2 wastewater appears highly turbid before pre-treatment (Fig. 2). A combination of (GAC) filtration and a $0.1-\mu \mathrm{m}$ PVDF membrane filter showed efficient removal of solid and colloidal particles, resulting in clear appearance wastewater (Fig. 2).

\section{Process limitation by metal deficiency}

An experimental run of $45 \mathrm{~L}$ PBR with KA2 wastewater and $N$. oleoabundans is shown in Fig. 3. The inoculum culture was grown for 1 week at $20{ }^{\circ} \mathrm{C}, 1 \% \mathrm{CO}_{2}$ atmosphere, BG11 growth medium at the PPFD of $150 \mu \mathrm{mol}$ photons $\mathrm{m}^{-2} \mathrm{~s}^{-1}$, and $2 \mathrm{~L}$ of inoculum culture was used to start the reactor. The batch phase started with a lag of 2.5 days. During the lag phase, significant chlorophyll loss was observed, as shown by the OD $680 \mathrm{~nm}$ readings. This was observed with inoculum introduced to a wastewater with an $\mathrm{NH}_{4}{ }^{+}$concentration exceeding $80 \mathrm{mg} \mathrm{L}^{-1}$ (Fig. 3, Batch Phase). 


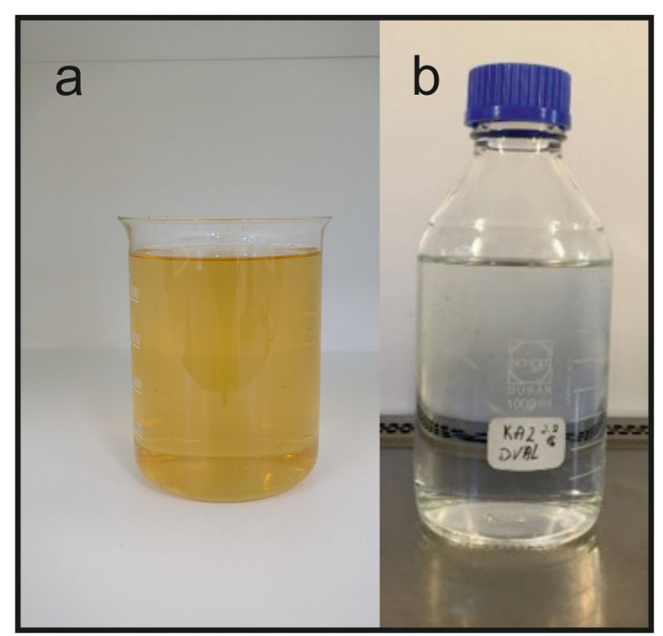

Fig. 2 KA2 wastewater, provided by HSY, Helsinki, Finland. a Raw KA2 wastewater. b KA2 after pre-treatment with GAC filtration unit and $0.1 \mu \mathrm{m}$ PVDF membrane filter

After the lag phase, growth started and significant biomass accumulated, indicating the acclimation of the culture to the wastewater (Fig. 3, Batch Phase). After 6 days of batch growth, turbidostat operation was started at the biomass concentration of around $0.5 \mathrm{~g} \mathrm{~L}^{-1}$. After $24 \mathrm{~h}$ of continuous run, the productivity of the system based on algal growth rate showed significant decrease, as measured by the dilution rate (Fig. 3, Turbidostat phase). Since the current research did not have the facilities to obtain detailed elemental analysis of the wastewater, in order to identify the missing component in the wastewater, the system was brought back to batch mode, diluted with wastewater to the biomass concentration of $0.2 \mathrm{~g} \mathrm{~L}^{-1}$, and then micronutrients (based on BG11 recipe) were introduced one by one in the following order: $\mathrm{K}, \mathrm{Ca}$, $\mathrm{Mg}$, trace metal mix, and Fe. After each addition of a micronutrient compound, the culture was left for $24 \mathrm{~h}$ to respond by growth indicated by the $\mathrm{OD}_{880}$ sensor. The response seen in Fig. 3 was achieved after the addition of $0.6 \mathrm{mg} \mathrm{L}^{-1}$ of ferric ammonium citrate (half concentration of the BG11 recipe), indicating that the growth was suppressed by the lack of iron.

Interestingly, the algae grew rapidly, producing $0.465 \pm$ $0.007 \mathrm{~g} \mathrm{~L}^{-1}$ during the initial 6-day batch phase, indicating that

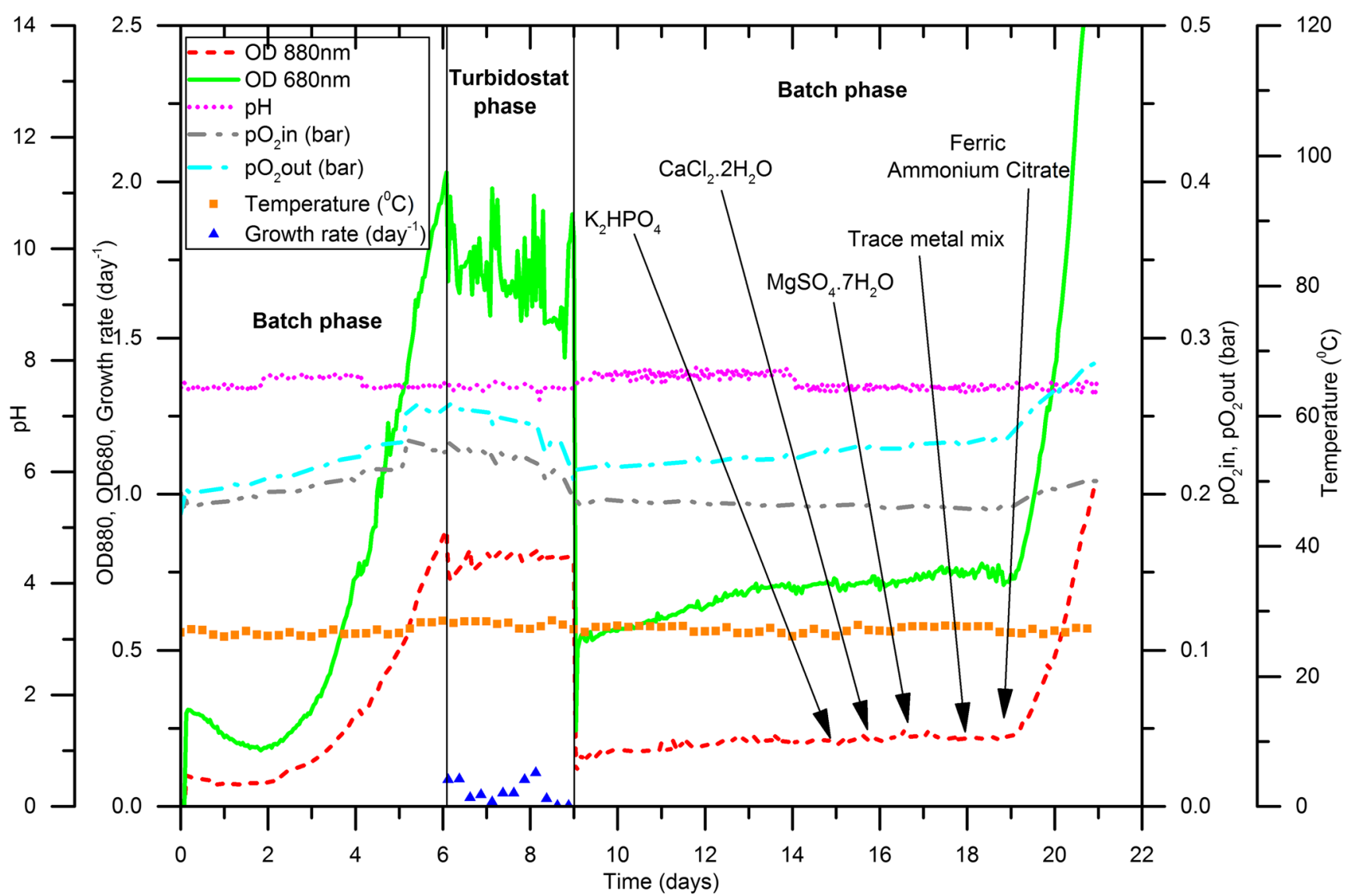

Fig. 3 First experiment with $45 \mathrm{~L}$ upscale tubular photobioreactor, KA2 wastewater, and $N$. oleoabundans. The experiment consists of an initial batch phase, followed by a short turbidostat phase and a second batch phase, as indicated. Optical density at $880 \mathrm{~nm}(---)$, optical density at $680 \mathrm{~nm}(-), \mathrm{pH}(\bullet \bullet)$, temperature (squares), oxygen concentration after the degasser $(-\bullet \bullet)$, oxygen concentration before the degasser after the photoactive part of the reactor $(-\bullet)$. The arrows show additions of nutrients during the second batch phase, including $\mathrm{K}_{2} \mathrm{HPO}_{4}$ $\left(0.23 \mathrm{mmol} \mathrm{L}^{-1}\right), \mathrm{CaCl}_{2}\left(0.24 \mathrm{mmol} \mathrm{L}^{-1}\right), \mathrm{MgSO}_{4}\left(0.3 \mathrm{mmol} \mathrm{L}^{-1}\right)$, ferric ammonium citrate $\left(0.021 \mathrm{mmol} \mathrm{L}^{-1}\right)$ and "BG11 trace metal mix" $\left(\mathrm{H}_{3} \mathrm{BO}_{3}\left(46 \mu \mathrm{mol} \mathrm{L}{ }^{-1}\right), \mathrm{MnCl}_{2}\left(9 \mu \mathrm{mol} \mathrm{L}{ }^{-1}\right), \mathrm{ZnSO}_{4}\left(0.77 \mu \mathrm{mol} \mathrm{L}{ }^{-1}\right)\right.$, $\mathrm{Na}_{2} \mathrm{MoO}_{4}\left(1.6 \mu \mathrm{mol} \mathrm{L}{ }^{-1}\right), \mathrm{CuSO}_{4}\left(0.3 \mu \mathrm{mol} \mathrm{L}{ }^{-1}\right), \mathrm{Co}\left(\mathrm{NO}_{3}\right)_{2}$ $\left.\left(0.17 \mu \mathrm{mol} \mathrm{L}{ }^{-1}\right)\right)$ 
the iron present in the inoculum (4.4\% of PBR volume), obtained by growing the algae in BG11, prevented the iron limitation from affecting the growth rate in the initial phase of the experiment.

Based on all observations described above, a new experiment was started (Fig. 4). To avoid masking limiting factors during batch from the addition of an inoculum grown in BG11, the inoculum culture was grown in KA2 wastewater with addition of $21 \mu \mathrm{mol} \mathrm{L}{ }^{-1}$ of ferric ammonium citrate. Again, the inoculum was cultivated for 1 week at $20{ }^{\circ} \mathrm{C}, 1 \% \mathrm{CO}_{2}$ and at PPFD $150 \mu \mathrm{mol}$ photons $\mathrm{m}^{-2} \mathrm{~s}^{-1}$, and the reactor was inoculated with $2 \mathrm{~L}$ of the inoculum. This experiment showed no prolonged lag phase during batch, and the culture growth started immediately. However, 4 days after inoculation, growth started to slow down, as indicated by the reading of the $\mathrm{OD}_{880}$ sensor. The biomass concentration was still so low that light limitation could not be the main cause for the decrease in growth. Since iron was introduced last from the list of BG11 components in the previous experiment, other limiting elements would stay hidden. Therefore, a mixture of micronutrients ( $\mathrm{B}$ (final concentration in PBR $\left.46 \mu \mathrm{mol} \mathrm{L}{ }^{-1}\right), \mathrm{Mn}\left(9 \mu \mathrm{mol} \mathrm{L}{ }^{-1}\right), \mathrm{Zn}\left(0.77 \mu \mathrm{mol} \mathrm{L}^{-1}\right), \mathrm{Mo}$
(1.6 $\left.\mu \mathrm{mol} \mathrm{L}{ }^{-1}\right), \mathrm{Cu}\left(0.3 \mu \mathrm{mol} \mathrm{L}{ }^{-1}\right)$, and $\mathrm{Co}\left(0.17 \mu \mathrm{mol} \mathrm{L}{ }^{-1}\right)$, according to BG11 recipe) was injected in the system. Recovery of the growth shows that there was at least one more component in addition to iron, essential for the algal growth, whose concentration in the wastewater was too low for continuous cultivation.

Due to the observed metal deficiencies, the complete "trace metal mix," used for preparation of BG11 growth medium, was added to the feeding wastewater for further experiments.

\section{Steady wastewater treatment process and ammonium and phosphate removal efficiencies}

Figure 5 shows a complete experiment with $N$. oleoabundans and KA2. The inoculum was grown in BG11 for 1 week at $20{ }^{\circ} \mathrm{C}, 1 \% \mathrm{CO}_{2}$ atmosphere, and the PPFD of $150 \mu \mathrm{mol}$ photons $\mathrm{m}^{-2} \mathrm{~s}^{-1}$, and the $45 \mathrm{~L}$ tubular PBR was inoculated with 2 L. Based on these empirical observations stated above, the macro and micronutrients were adjusted in the feeding wastewater accordingly. In addition to adding iron and the trace metal mix in the same final concentrations as in BG11, the

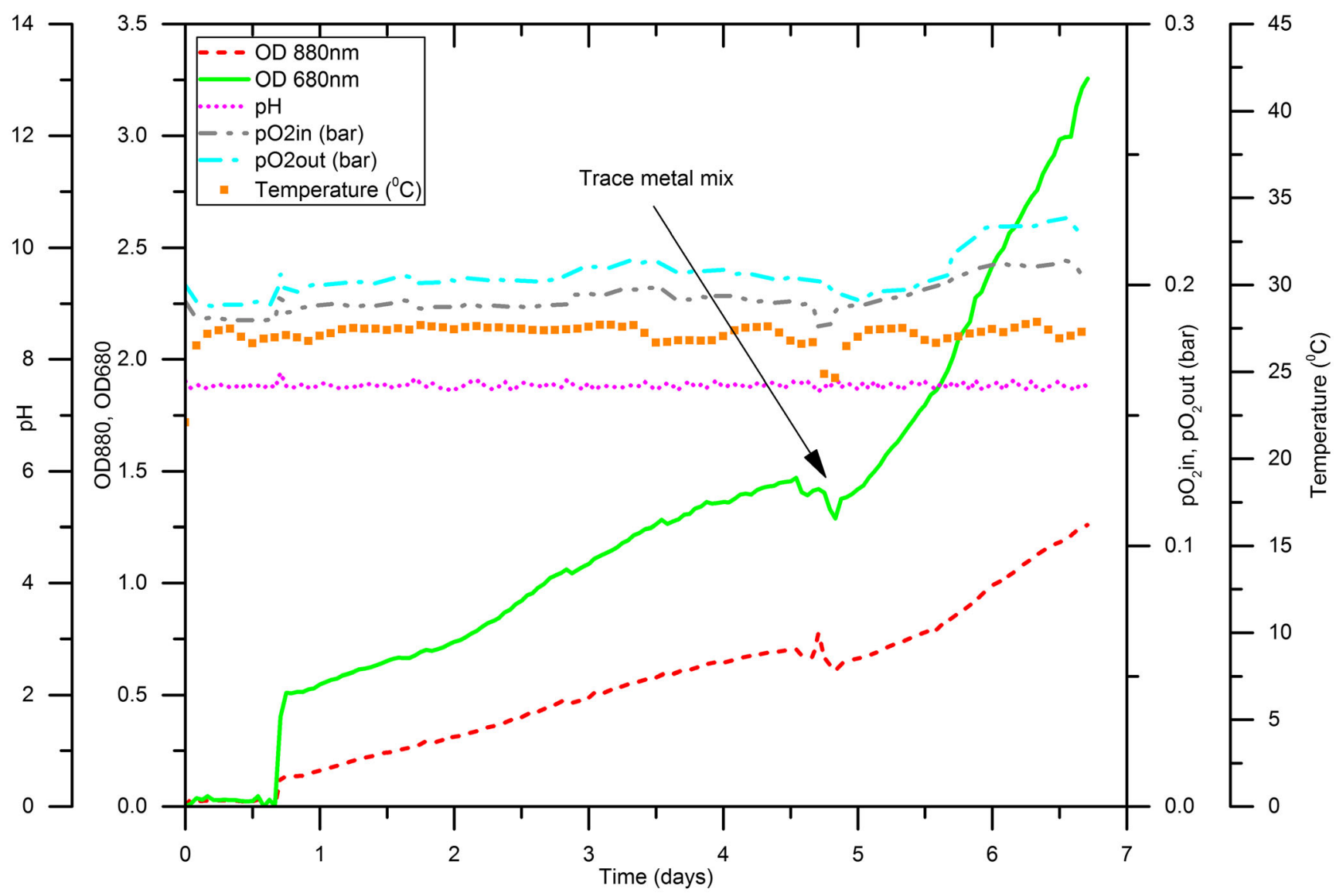

Fig. 4 Second experiment with $45 \mathrm{~L}$ upscale tubular photobioreactor, KA2 wastewater, and $N$. oleoabundans. The experiment shows batch growth of $N$. oleoabundans in KA2 wastewater with added ferric ammonium citrate (final concentration $0.021 \mathrm{mM}$ ). Optical density at $880 \mathrm{~nm}(---)$, optical density at $680 \mathrm{~nm}(-), \mathrm{pH}(\bullet \bullet)$, temperature (squares), oxygen concentration after the degasser $(-\bullet \bullet)$, oxygen concentration before the degasser after the photoactive part of the reactor (- $)$. The arrow shows the addition of "BG11 trace metal mix" $\left(\mathrm{H}_{3} \mathrm{BO}_{3}(46 \mu \mathrm{mol} \mathrm{L}-1), \mathrm{MnCl}_{2}(9 \mu \mathrm{mol} \mathrm{L}-1), \mathrm{ZnSO}_{4}\left(0.77 \mu \mathrm{mol} \mathrm{L}{ }^{-1}\right)\right.$, $\mathrm{Na}_{2} \mathrm{MoO}_{4}\left(1.6 \mu \mathrm{mol} \mathrm{L}{ }^{-1}\right), \mathrm{CuSO}_{4}\left(0.3 \mu \mathrm{mol} \mathrm{L}{ }^{-1}\right), \mathrm{Co}\left(\mathrm{NO}_{3}\right)_{2}$ $\left.\left(0.17 \mu \mathrm{mol} \mathrm{L}{ }^{-1}\right)\right)$ 


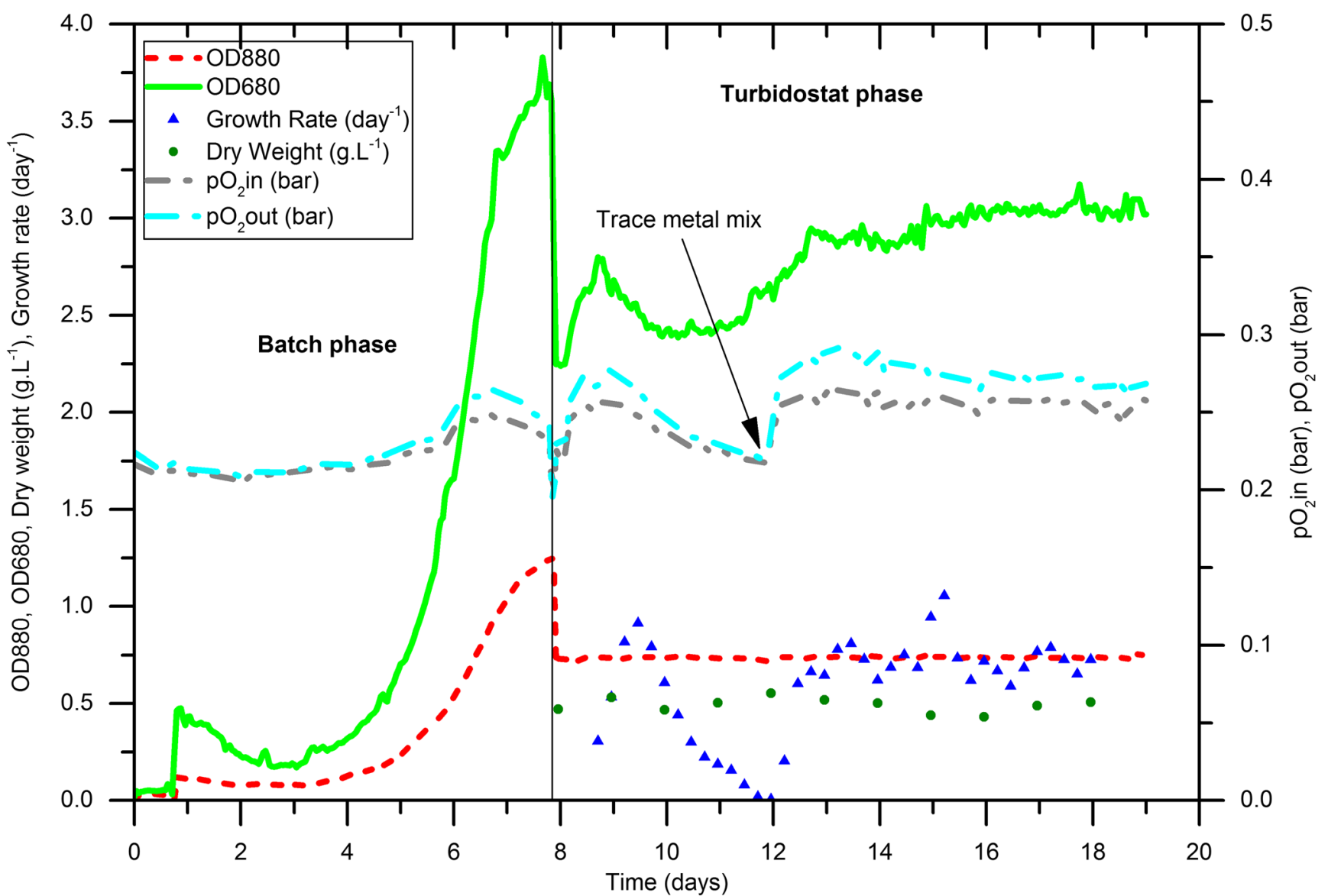

Fig. 5 Third experiment with $45 \mathrm{~L}$ upscale tubular photobioreactor, KA2 wastewater, and $N$. oleoabundans. The BG11 trace metal mix $\left(\mathrm{H}_{3} \mathrm{BO}_{3}\right.$, $\mathrm{MnCl}_{2}, \mathrm{ZnSO}_{4}, \mathrm{Na}_{2} \mathrm{MoO}_{4}, \mathrm{CuSO}_{4}, \mathrm{Co}\left(\mathrm{NO}_{3}\right)_{2}$; see the legend of Fig. 4 for the concentrations) was initially added to the wastewater storage container. The experiment consists of an initial batch phase, followed by a turbidostat phase, as indicated. Optical density at $880 \mathrm{~nm}(---)$,

concentrations of $\mathrm{PO}_{4}{ }^{3-}$ and $\mathrm{SO}_{4}{ }^{2-}$ of the feeding wastewater were also adjusted. The two macronutrients were added as $\mathrm{K}_{2} \mathrm{HPO}_{4}$ and $\mathrm{KSO}_{4}$ to concentrations similar to those of $\mathrm{BG11}$.

The concentrations of macronutrients $\left(\mathrm{NH}_{4}{ }^{+}, \mathrm{NO}_{3}{ }^{-}, \mathrm{PO}_{4}{ }^{3-}\right.$, and $\mathrm{SO}_{4}{ }^{2-}$ ) were measured during the batch phase (Fig. 6). The starting ammonium concentration was $105.2 \mathrm{mg} \mathrm{L}^{-1}$ (5.83 $\mathrm{mmol} \mathrm{L}^{-1}$ ), and the adjusted starting concentrations of $\mathrm{PO}_{4}{ }^{3-}$ and $\mathrm{SO}_{4}{ }^{2-}$ were $24.98 \mathrm{mg} \mathrm{L}^{-1}\left(0.26 \mathrm{mmol} \mathrm{L}^{-1}\right)$ and $29.11 \mathrm{mg} \mathrm{L}^{-1}\left(0.3 \mathrm{mmol} \mathrm{L}^{-1}\right)$, respectively. $\mathrm{No} \mathrm{NO}_{3}{ }^{-}$was present in the wastewater prior to inoculation, but the inoculum brought some nitrate to the wastewater medium (Fig. 6). There were no significant changes in nutrient concentrations during the extended lag phase. At day $4, N$. oleoabundans cells had acclimated to the wastewater and started growing, as indicated by increase in biomass (Fig. 6). At the same time, the readings of the $\mathrm{OD}_{880}$ sensor and the chlorophyll content, indicated by the $\mathrm{OD}_{680}$ sensor, increased hand in hand, indicating a healthy culture (Fig. 5, batch phase). The concentrations of $\mathrm{NH}_{4}^{+}$and $\mathrm{PO}_{4}^{3-}$ decreased slowly during the lag phase and the concentration of $\mathrm{SO}_{4}{ }^{2-}$ remained unchanged. When rapid optical density at $680 \mathrm{~nm}(-), \mathrm{pH}(\bullet \bullet)$. oxygen concentration after the degasser $(-\bullet \cdot)$, oxygen concentration before the degasser after the photoactive part of the reactor $(-\bullet)$, biomass dry weight measured from daily samples (circles), growth rate calculated from the dilution rate (triangles). The arrow shows the addition of BG11 trace metal mix directly to the photobioreactor

growth of the algae started on day 4 , the algae consumed all $\mathrm{PO}_{4}{ }^{3-}$ in 2 days, all $\mathrm{SO}_{4}{ }^{2-}$ in 3 days, and all $\mathrm{NH}_{4}{ }^{+}$in 4 days (Fig. 6). The $\mathrm{NO}_{3}{ }^{-}$concentration started to decline only when virtually all $\mathrm{NH}_{4}{ }^{+}$had been consumed.

The turbidostat phase was started after the batch phase (Fig. 5). The concentrations of the macro and micronutrients in the wastewater was adjusted by addition of ferric ammonium citrate to a final concentration of $0.27 \mathrm{~g} \mathrm{~L}^{-1}\left(0.021 \mathrm{mmol} \mathrm{L}^{-1}\right)$, a trace metal mix (according to BG11 recipe), $33.7 \mathrm{mg} \mathrm{L}^{-1} \mathrm{SO}_{4}{ }^{2-}$ $\left(0.35 \mathrm{mmol} \mathrm{L}^{-1}\right) . \mathrm{PO}_{4}{ }^{3-}$ concentration was adjusted once again to $33.95 \mathrm{mg} \mathrm{L}^{-1}\left(0.357 \mathrm{mmol} \mathrm{L}^{-1}\right)$. After $24 \mathrm{~h}$ of turbidostat operation, $\mathrm{O}_{2}$ production (indicated by a difference between the $\mathrm{O}_{2}$ concentration of the outgoing algal suspension and ingoing wastewater medium) started to decrease (Fig. 5). At the same time, a decrease in the dilution rate indicated rapid decrease in the productivity of the system. The $\mathrm{F}_{\mathrm{V}} / \mathrm{F}_{\mathrm{M}}$ value, obtained by measuring a sample from the PBR, was 0.334. In order to recover the growth, trace metal mix solution was next introduced directly into the PBR at the same final concentrations as achieved with the addition of the same mix to the supply tank. The addition led to 


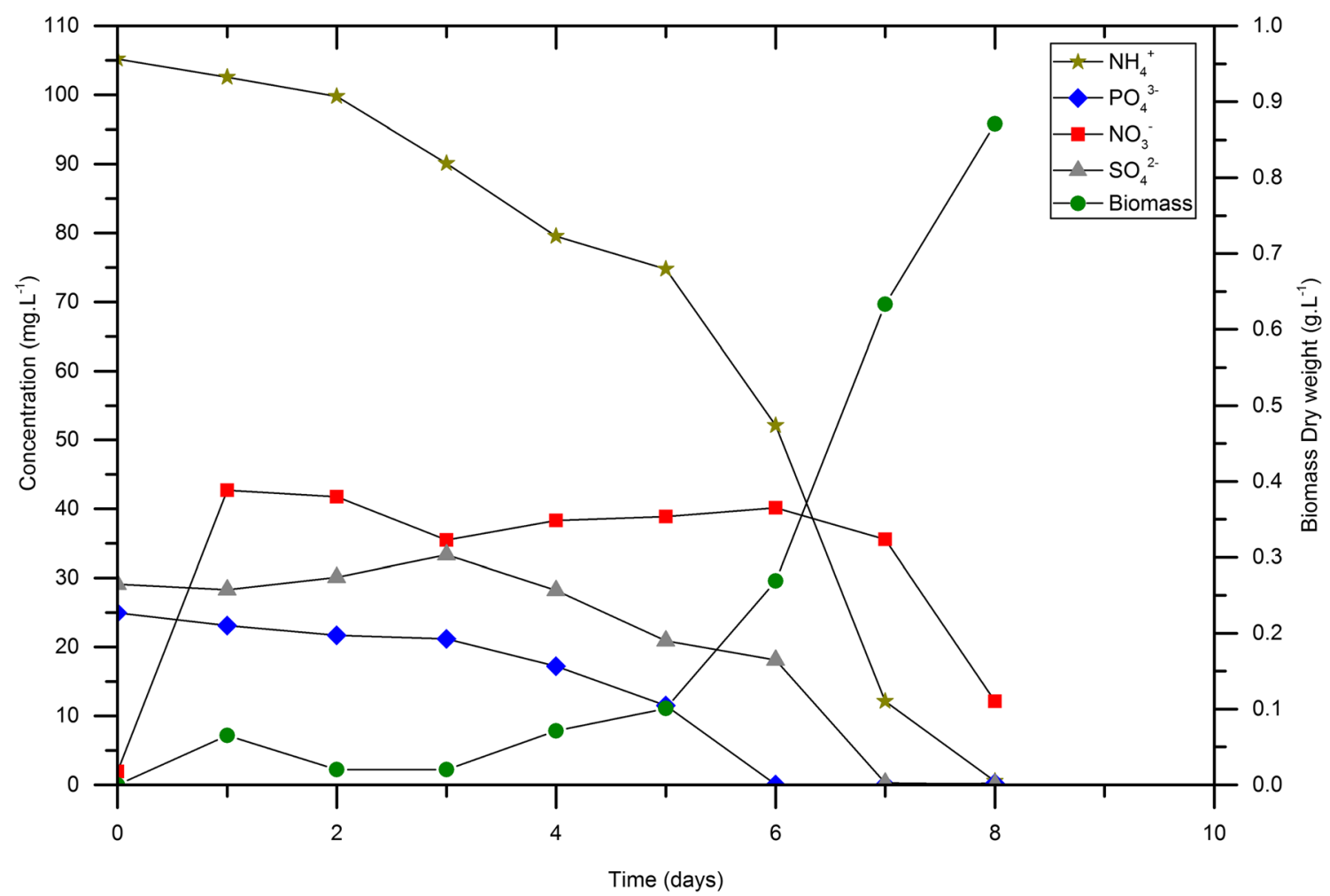

Fig. 6 Concentrations of nutrients and biomass in the tubular photobioreactor during the batch phase of the third upscale experiment. $\mathrm{NH}_{4}{ }^{+}$(star), $\mathrm{PO}_{4}{ }^{3-}$ (rhombus), $\mathrm{NO}_{3}{ }^{-}$(square), $\mathrm{SO}_{4}{ }^{2-}$ (triangle), biomass dry weight (circle). Macronutrients were spectrophotometrically analyzed

detectable increase in oxygen production within $10 \mathrm{~min}$, and $12 \mathrm{~h}$ later, oxygen evolution and algal growth had recovered completely (Fig. 5). $\mathrm{F}_{\mathrm{V}} / \mathrm{F}_{\mathrm{M}}$ value of 0.76 remained stable, when measured on a daily base, during the stable part of the turbidostat. After this, the process went on uninterrupted for 7 days, until all wastewater prepared for the experiment had been depleted. Influent and effluent $\mathrm{NH}_{4}{ }^{+}$and $\mathrm{PO}_{4}{ }^{3-}$ concentrations measured from the supply tank and the PBR remained steady for $5 \times$ HRT (Fig. 7). However, bio-flocculation on the inner reactor surface had occurred during the trace metal limitation part of the experiment. During the steady turbidostat operation, after recovery from nutrient deficiency (from day 12 on in Fig. 5), the nutrient removal efficiencies of the PBR were $75 \%$ for $\mathrm{NH}_{4}{ }^{+}$and $99.6 \%$ for $\mathrm{PO}_{4}{ }^{3-}$ (Fig. 7). With the average biomass concentration of $0.47 \mathrm{~g} \mathrm{~L}^{-1}$ and average growth rate of 0.73 day $^{-1}$, the average biomass productivity during the stable process operation was $0.34 \mathrm{~g} \mathrm{~L}^{-1}$ day $^{-1}$.

\section{Discussion}

\section{Importance of wastewater pre-treatment}

The GAC filtration is an efficient method for organic and turbidity removal from wastewaters (Metcalf \& Eddy et al. 2004; on a daily base during the batch phase from samples collected from the photobioreactor. The dry weight measurements were also used to calibrate the OD880 sensor for use during the turbidostat phase

Hatt et al. 2013) and has little or no effect over ammonium, nitrate, or phosphorus content of wastewaters (Metcalf \& Eddy et al. 2004, Table 11-2). However, adsorption via granular activated carbon is known as to be used for removal of heavy metal ions from wastewaters. When well optimized, GAC can account for $99.02 \%$ and $79.05 \%$ of iron and manganese removal efficiencies, respectively (Goher et al. 2015). Therefore, this adsorption process would change the metal composition of the wastewater. In some cases, it will be beneficial to apply metal removal as pre-treatment in an alga-based wastewater treatment process, as high metal concentrations can be toxic to microalgae (Arunakumara and Zhang 2008). On the other hand, the CAG treatment may deprive microalgae from essential micronutrients. It was found that the turbidity could be removed by using either the PVDF filter or the GAC unit alone, but the GAC filter was developed to extend the life of the single-use PVDF membrane filter, whereas the PVDF filter was needed for removal of microorganisms.

We are taking into account that our choice of pre-treatment method for the wastewater by adsorption with granular activated carbon changes the composition of the raw wastewater, especially by lowering the metal content. However, pretreatment is crucial to establish a reliable, stable, and efficient process. It is necessary in order to remove TSS and turbidity since they would reduce the light available for photosynthesis 


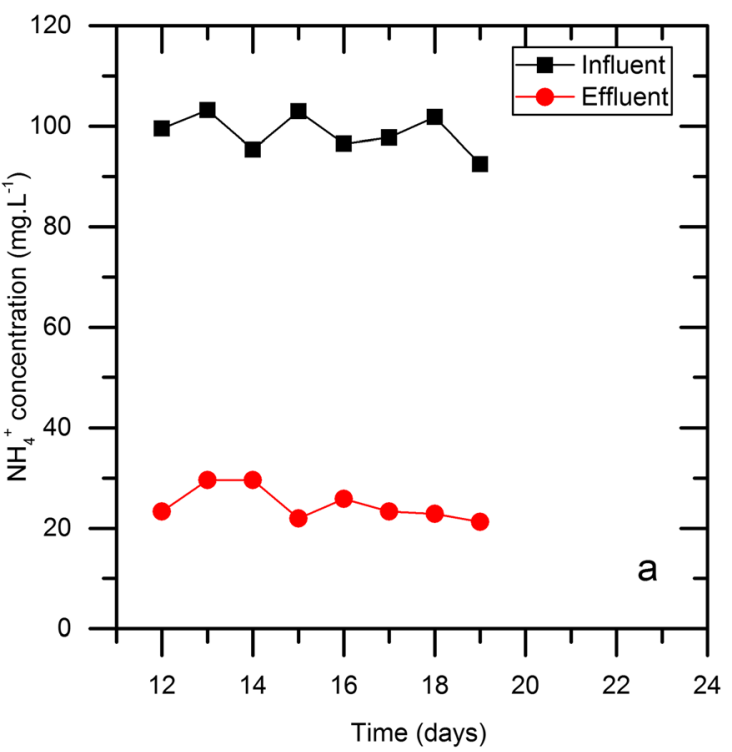

Fig. 7 Influent (squares) and effluent (circles) ammonium (a) and phosphate (b) concentration during the stable turbidostat phase of the third upscale experiment. The measurements were done from samples

in the PBR and thereby compromise the productivity of the system. Any type of pre-treatment would impact the final wastewater composition. Therefore, it would be very useful to perform a detailed analysis of the wastewaters after the pretreatment, focused on micronutrients. In the present work, empirical observations about the responses of the algae to different nutrients were used to establish which micronutrients limited algal growth.

\section{Process limitation by metal deficiency}

A long lag phase, as observed during the first upscale experiment (Fig. 3), has been observed by other researchers. A similar growth behavior during batch has been reported for the diatom Nitzschia pungens, the dinoflagellate Alexandrium catenella, and the green alga Scenedesmus sp. (Bates et al. 1993; Collos et al. 2004; Park et al. 2010). The duration of the lag phase is correlated with the initial ammonium concentration, and high $\mathrm{NH}_{4}{ }^{+}$concentrations lead to a long lag. However, the same studies show that a long lag phase does not affect the specific growth rate of the culture after acclimation to the high ammonium concentration.

Even though uptake of micronutrient from wastewaters by $N$. oleoabundans was not the main aim of the present study, our findings about the micronutrients proved to be major steps towards better understanding of the design and operation of wastewater treatment with microalgae. Furthermore, the success of the batch growth and failure of subsequent continuous growth in the same wastewater indicates that batch growth may not predict the ability to maintain a continuous culture. Therefore, in order to investigate properly the ability of algae to grow in a particular wastewater, one should either prepare

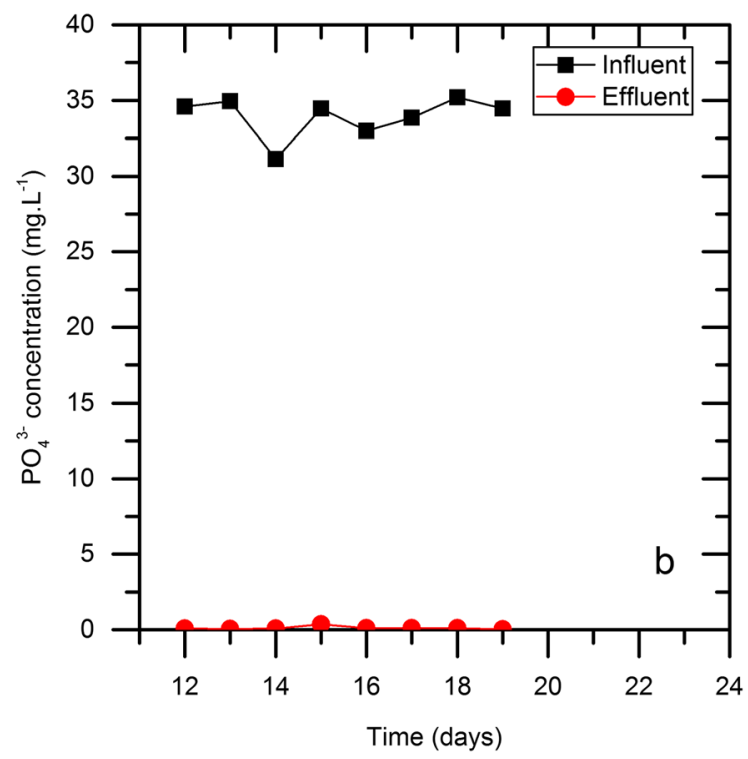

collected directly from the PBR, after recovery of the system productivity from trace metal limitation (see Fig. 5)

the inoculum in the same wastewater or use turbidostat growth. In addition to potentially revealing nutrient limitations of the wastewater already during the batch phase, the use of wastewater as growth medium for the inoculum would give the additional advantage of acclimating the algal culture to the given ammonium concentration, which is expected to shorten the lag phase. The observations of the current study shows that if an optimal growth medium, such as BG11, is used for the preparation of the inoculum, only the continuous phase of the experiment will reliably reveal nutrient limitations.

Slow growth and slow increase in the chlorophyll content before the addition of iron indicated in Fig. 3 suggest that iron was present in the wastewater but in too low concentration. The iron concentration of BG11 is $21 \mu \mathrm{mol} \mathrm{L}{ }^{-1}$, and therefore, the inoculum used for this experiment contained $42 \mu \mathrm{mol}$ (2.345 mg) Fe. At the end of the batch phase, the PBR contained $23.8 \mathrm{~g}$ dry biomass. As the Fe content of marine algal biomass is reported as $1-7 \%$ (Fabregas and Herrero 1986), approximated calculations based on these data indicated that the algae contained at least $0.4 \mathrm{mmol}(22.5 \mathrm{mg}) \mathrm{Fe}$ after the batch. By taking into consideration the amount of iron which was added during the batch and the $42 \mu \mathrm{mol}$ added with the inoculum, it was calculated that the iron content in the wastewater was at least $8.3 \mu \mathrm{M}(400-42 \mu \mathrm{mol}$ per $43 \mathrm{~L})$. This is not a low concentration for algal growth, as many marine algae can be cultivated at $0.3 \mu \mathrm{mol} \mathrm{L}{ }^{-1} \mathrm{Fe}$ (Botebol et al. 2017). However, the observation that iron deficiency was detected immediately upon starting continuous growth indicates that the algae had consumed virtually all iron of the wastewater during the batch phase, and the continuous additions of wastewater did not bring enough iron to the medium to support the continuous phase. 
During the second upscale experiment (Fig. 4), limitation by another heavy metal was revealed. However, it is not possible to specify which one of the components of the micronutrient mix of BG11 was limiting the growth of N. oleoabundans. Among these elements, boron may not be essential, as previous studies with green algae have revealed no differences in their growth in $\mathrm{B}$ free and $\mathrm{B}$ replete media, and no absorption of $\mathrm{B}$ occurred when cells were grown in boron containing medium (Gerloff 1968). Cobalt is a central ion in cobalamin (vitamin B12) that plays important roles in DNA synthesis and in the metabolism of fatty acids and amino acids. BG11 is designed for fully autotrophic organisms that can synthetize vitamin B12, but some microalgae need an external source of cobalamin (Croft et al. 2006). Neochloris pseudoalgeolaris, a relative of $N$. oleoabundans, does not require vitamin B12 but has a higher chlorophyll content when cultivated in its presence (Easley 1969). In the present experiments, no vitamin B12 was added to the growth medium of $N$. oleoabundans.

\section{Steady wastewater treatment process and ammonium and phosphate removal efficiencies}

For the final upscale experiment as mentioned, $\mathrm{PO}_{4}{ }^{3-}$ and $\mathrm{SO}_{4}{ }^{2-}$ were added to the wastewater since their concentrations in KA2 wastewater, especially that of phosphate, were obviously too low for stable algal growth (Table 2). Furthermore, the consumption of macronutrients during the batch phase was used as a guideline for calculating the need of these nutrients during the subsequent turbidostat phase. The sulfur and phosphorus concentrations of $N$. oleoabundans are $0.014 \mathrm{~mol}$ and $0.012 \mathrm{~mol}(\mathrm{~mol} \mathrm{C})^{-1}$, or $\sim 0.6 \mathrm{mmol} \mathrm{S}$ and $\sim 0.51 \mathrm{mmol} \mathrm{P}$ per $\mathrm{g}$ biomass, based on the information that $N$. oleoabundans contains $1 \mathrm{~mol} \mathrm{C}$ per $23.45 \mathrm{~g}$ of biomass (Pruvost et al. 2009). Hence, $0.3 \mathrm{mmol} \mathrm{L}^{-1}$ of sulfate would be sufficient to run the turbidostat phase of the experiment at a biomass concentration of approximately $0.5 \mathrm{~g} \mathrm{~L}^{-1}$. However, $N$. oleoabundans has absorbed more phosphate than expected at the given biomass concentration. At day 6 of the batch phase (Fig. 6), all phosphate, $24.98 \mathrm{mg} \mathrm{L}^{-1}$ $\left(0.26 \mathrm{mmol} \mathrm{L}^{-1}\right)$, had been absorbed by the biomass concentration of $0.3 \mathrm{~g} \mathrm{~L}^{-1}$ and at day 7 , all $\mathrm{SO}_{4}{ }^{2-}$, initially $29.11 \mathrm{mg} \mathrm{L}^{-1}\left(0.3 \mathrm{mmol} \mathrm{L}^{-1}\right)$, was depleted by the time biomass has reached the concentration of $0.65 \mathrm{~g} \mathrm{~L}^{-1}$. Therefore, for the turbidostat phase of the experiment, phosphate concentration was increased to $33.95 \mathrm{mg} \mathrm{L}^{-1}$ $\left(0.357 \mathrm{mmol} \mathrm{L}^{-1}\right)$, in order to support the growth of biomass at the concentration of $0.5 \mathrm{~g} \mathrm{~L}^{-1}$. The adjusted phosphate concentration in the wastewater during the turbidostat operation corresponded to the Redfield N:P molar ratio of 16 (Redfield 1934). The sulfate concentration was kept at approximately $30 \mathrm{mg} \mathrm{L}^{-1}$. At the end of the batch phase (Fig. 6 ), the ammonium concentration of $105.2 \mathrm{mg} \mathrm{L}^{-1}$ $\left(5.83 \mathrm{mmol} \mathrm{L}^{-1}\right)$ was utilized by the culture for production of $0.9 \mathrm{~g} \mathrm{~L}^{-1}$ of biomass whereas the excess nitrate that was introduced at inoculation was consumed only at the end of the batch phase. It has been shown that $N$. oleoabundans shows better growth when cultured in a nitrate containing medium than in an ammonium containing medium ( $\mathrm{Li}$ et al. 2008). However, when Phaeodactylum tricornutum or Chlorella vulgaris is grown in a medium containing ammonium and nitrate, the cultures first absorb the ammonium until depletion, and only then nitrate (Morris and Syrett 1963; Cresswell and Syrett 1982). It is considered that a product of ammonium assimilation reversibly inactivates nitrate transporters and nitrate reductase (Morris and Syrett 1963; Losada et al. 1970; Cresswell and Syrett 1979).

The troubling early stages of turbidostat operation, associated with low $\mathrm{O}_{2}$ production, rapid decrease in the productivity of the system and measured $F_{V} / F_{M}$ value of only 0.334 , indicated suppression of photosynthesis (Fig. 5). A low $F_{V} / F_{M}$ value indicates a poor performance of the photosynthetic apparatus in green microalgae, whereas value of 0.76 that was measured during steady turbidostat process shows healthy algal cells (White et al. 2011; Szabó et al. 2014). It has been shown that photosynthetic fluorescence parameters can be used as a stress marker in algal cultivation systems. High temperature above $32{ }^{\circ} \mathrm{C}$, high irradiance, and high $\mathrm{pH}$ (low $\mathrm{CO}_{2}$ ) have decreased $\mathrm{F}_{\mathrm{V}} / \mathrm{F}_{\mathrm{M}}$ values during outdoor cultivation of Nannochloropsis sp. (Kromkamp et al. 2009; Sukenik et al. 2009). In our experiments, irradiance was constant (artificial illumination), $\mathrm{pH}$ was kept steady at 7.5 , and temperature never exceeded $30{ }^{\circ} \mathrm{C}$. Therefore, the low productivity suggested that nutrients did not reach the algae properly, and to solve the problem, the trace metal mix solution was
Table 2 Macronutrient analysis of pre-filtered KA2 wastewater before and after adjustment of $\mathrm{PO}_{4}{ }^{3-}$ and $\mathrm{SO}_{3}{ }^{2-}$ concentrations for the batch and turbidostat phases of the third upscale experiment. N.d. indicates that the concentration was below the detection limit

\begin{tabular}{|c|c|c|c|c|c|c|}
\hline & \multicolumn{2}{|l|}{ Raw KA2 } & \multicolumn{2}{|c|}{$\begin{array}{l}\text { KA2 after adjustment (batch } \\
\text { phase) }\end{array}$} & \multicolumn{2}{|c|}{$\begin{array}{l}\text { KA2 after adjustment (turbidostat } \\
\text { phase) }\end{array}$} \\
\hline & $\mathrm{mg} \mathrm{L}^{-1}$ & $\overline{\mathrm{mmol} \mathrm{L}^{-1}}$ & $\mathrm{mg} \mathrm{L}^{-1}$ & $\mathrm{mmol} \mathrm{L}^{-1}$ & $\mathrm{mg} \mathrm{L}^{-1}$ & $\mathrm{mmol} \mathrm{L}^{-1}$ \\
\hline $\mathrm{NH}_{4}^{+}$ & $110.4 \pm 1.35$ & 5.86 & 105.2 & 5.83 & $98.68 \pm 3.84$ & $5.47 \pm 0.21$ \\
\hline $\mathrm{NO}_{3}^{-}$ & N.d. & N.d. & 1.94 & 0.03 & $2.19 \pm 1.6$ & $0.035 \pm 0.025$ \\
\hline $\mathrm{PO}_{4}{ }^{3-}$ & $6.93 \pm 0.017$ & 0.07 & 24.98 & 0.26 & $33.95 \pm 1.33$ & $0.36 \pm 0.014$ \\
\hline $\mathrm{SO}_{4}{ }^{2-}$ & 17.83 & 0.18 & 29.11 & 0.30 & 33.67 & 0.35 \\
\hline
\end{tabular}


introduced directly into the PBR at the same final concentrations as achieved with the addition of the same mix to the supply tank. Recovery of the process suggests that chelating of the metals and subsequent sedimentation may have occurred during the 48-h storage of the wastewater in the supply tank. The data recorded before the addition of the trace metals also show that stress caused by micronutrient limitation has a negative effect on the photosynthetic performance of $N$. oleoabundans. To avoid such loss of the metals, the wastewater supply was changed to $20 \mathrm{~L}$ batches that were renewed and adjusted for metal content daily. The resulting flocculation of biomass on the reactor walls has been observed during our earlier experiments with $N$. oleoabundans. This species easily flocculates when exposed to stress conditions like rapid temperature changes, low inorganic carbon concentration, or high light.

During the steady turbidostat process, all phosphate was utilized by $0.47 \mathrm{~g} \mathrm{~L}^{-1}$ of biomass while $25-30 \mathrm{mg} \mathrm{L}^{-1}$ of ammonium remained in the effluent wastewater (Fig. 7). $N$. oleoabundans cells absorbed $74 \mathrm{mg} \mathrm{L}^{-1}\left(4.1 \mathrm{mmol} \mathrm{L}^{-1}\right)$ of ammonium, and $33.8 \mathrm{mg} \mathrm{L}^{-1}\left(0.356 \mathrm{mmol} \mathrm{L}^{-1}\right)$ of phosphate, resulting in N/P molar ratio of 11.5 which is close to the N/P ratio of 12.3 earlier shown by Pruvost et al. (2009) for $N$. oleoabundans biomass. Based on the biomass composition of $N$. oleoabundans determined by Pruvost et al. (2009), a biomass productivity of $0.34 \mathrm{~g} \mathrm{~L}^{-1}$ day ${ }^{-1}$ should account for $2.16 \mathrm{mmol} \mathrm{L}^{-1}$ of inorganic nitrogen and $0.176 \mathrm{mmol} \mathrm{L}^{-1}$ of inorganic $\mathrm{P}$ utilized by the algal cells for the production of new biomass. The extra nitrogen absorbed by the microalgae is obviously due to the high phosphorus concentration of the wastewater. It has been reported that increasing the inorganic phosphorus concentration will promote higher inorganic nitrogen uptake (Michels et al. 2014). However, further increase of the phosphate concentration in our experiment at this biomass concentration would not promote higher $\mathrm{NH}_{4}{ }^{+}$uptake (Michels et al. 2014). Achieving close to $100 \%$ ammonium removal would be possible at higher biomass concentration with corresponding adjustment of the phosphate concentration for N/P molar ratio of 12.

\section{Conclusions}

Establishing stable wastewater treatment processes with microalgae is an optimistic possibility in near future. Implementing conventional wastewater pre-treatment and determining possible limiting factors such as metal concentrations and N/P ratio are crucial steps towards an efficient and stable process. When such a process is well optimized, it could reach close to $100 \%$ of recovery of macronutrients via incorporation in the algal biomass. Further in-depth analysis of metal uptake can bring better estimation of the potential of microalgae for heavy metal removal from polluted waters. In order to have a complete understanding of the economic impact of such a process, the use of sunlight should be investigated in outdoor experiments.

Acknowledgments Aino Kainulainen, Christoph Careis, and Roni Järvensivu from Helsinki Region Environmental Services Authority (HSY) are thanked for cooperation with the wastewaters and Pasi Saarenmaa, Kurt Ståhle, and Tapio Ronkainen for cooperation in the construction of the photobioreactor.

Funding information Open access funding provided by University of Turku (UTU) including Turku University Central Hospital. Funding was by Academy of Finland (grant 307335) and HSY.

Open Access This article is distributed under the terms of the Creative Commons Attribution 4.0 International License (http:// creativecommons.org/licenses/by/4.0/), which permits unrestricted use, distribution, and reproduction in any medium, provided you give appropriate credit to the original author(s) and the source, provide a link to the Creative Commons license, and indicate if changes were made.

\section{References}

Arunakumara KKIU, Zhang X (2008) Heavy metal bioaccumulation and toxicity with special reference to microalgae. J Ocean Univ China 7: $60-64$

Barber J (2003) Photosystem II: the engine of life. Q Rev Biophys 36:7189

Bates SS, Worms J, Smith JC (1993) Effects of ammonium and nitrate on growth and domoic acid production by Nitzschia pungens in batch culture. Can J Fish Aquat Sci 50:1248-1254

Botebol H, Lelandais G, Six C, Lesuisse E, Meng A, Bittner L, Lecrom S, Sutak R, Lozano JC, Schatt P, Vergé V, Blain S, Bouget FY (2017) Acclimation of a low iron adapted Ostreococcus strain to iron limitation through cell biomass lowering. Sci Rep 7:327

Chirila E, Draghici C, Puhacel A (2014) Total and dissolved metals occurrence in municipal wastewater treatment plant effluents

Collos Y, Gagne C, Laabir M, Vaquer A, Cecchi P, Souchu P (2004) Nitrogenous nutrition of Alexandrium catenella (Dinophyceae) in cultures and in Thau lagoon, southern France. J Phycol 40:96-103

Cresswell RC, Syrett PJ (1979) Ammonium inhibition of nitrate uptake by the diatom, Phaeodactylum tricornutum. Plant Sci Lett 14:321325

Cresswell RC, Syrett PJ (1982) The uptake of nitrite by the diatom Phaeodactylum: interactions between nitrite and nitrate. J Exp Bot 33:1111-1121

Croft MT, Warren MJ, Smith AG (2006) Algae need their vitamins. Eukaryot Cell 5:1175 LP-1171183

de la Noüe J, Sevrin-Reyssac J, Mariojouls C, Marcel J, Sylvestre S (1994) Biotreatment of swine manure by intensive lagooning during winter. Bioresour Technol 50:213-219

Easley LW (1969) Modification of protein synthesis by vitamin B12 in the marine algal flagellate Neochloris pseudoalveolaris. J Protozool $16: 286-289$

Fabregas J, Herrero C (1986) Marine microalgae as a potential source of minerals in fish diets. Aquaculture 51:237-243

Fu F, Wang Q (2011) Removal of heavy metal ions from wastewaters: a review. J Environ Manag 92:407-418 
Gerloff GC (1968) The comparative boron nutrition of several green and blue-green algae. Physiol Plant 21:369-377

Goher ME, Hassan AM, Abdel-Moniem IA, Fahmy AH, Abdo MH, Esayed SM (2015) Removal of aluminum, iron and manganese ions from industrial wastes using granular activated carbon and Amberlite IR-120H. Egypt J Aquat Res 41:155-164

Hänsch R, Mendel RR (2009) Physiological functions of mineral micronutrients $(\mathrm{Cu}, \mathrm{Zn}, \mathrm{Mn}, \mathrm{Fe}, \mathrm{Ni}, \mathrm{Mo}, \mathrm{B}, \mathrm{cl})$. Curr Opin Plant Biol 12:259-266

Hatt JW, Germain E, Judd SJ (2013) Granular activated carbon for removal of organic matter and turbidity from secondary wastewater. Water Sci Technol 67:846-853

Huntley ME, Redalje DG (2007) $\mathrm{CO}_{2}$ mitigation and renewable oil from photosynthetic microbes: a new appraisal. Mitig Adapt Strateg Glob Chang 12:573-608

Karvelas M, Katsoyiannis A, Samara C (2003) Occurrence and fate of heavy metals in the wastewater treatment process. Chemosphere 53: $1201-1210$

Kligerman DC, Bouwer EJ (2015) Prospects for biodiesel production from algae-based wastewater treatment in Brazil: a review. Renew Sust Energ Rev 52:1834-1846

Kromkamp JC, Beardall J, Sukenik A, Kopecky J, Masojidek J, Van Bergeijk S, Gabai S, Shaham E, Yamshon A (2009) Short-term variations in photosynthetic parameters of Nannochloropsis cultures grown in two types of outdoor mass cultivation systems. Aquat Microb Ecol 56:309-322

Li Y, Horsman M, Wang B, Wu N, Lan CQ (2008) Effects of nitrogen sources on cell growth and lipid accumulation of green alga Neochloris oleoabundans. Appl Microbiol Biotechnol 81:629-636

Losada M, Paneque A, Aparicio PJ, Mvega J, Cardenas J, Herrera J (1970) Inactivation and repression by ammonium of the nitrate reducing system in Chlorella. Biochem Biophys Res Commun 38: 1009-1015

Mehta SK, Gaur JP (2005) Use of algae for removing heavy metal ions from wastewater: progress and prospects. Crit Rev Biotechnol 25: $113-152$

Metcalf \& Eddy, Tchobanoglous G, Burton LF, Stensel HD (2004) Wastewater engineering : treatment and reuse. McGraw-Hill, Boston

Michels MHA, Vaskoska M, Vermuë MH, Wijffels RH (2014) Growth of Tetraselmis suecica in a tubular photobioreactor on wastewater from a fish farm. Water Res 65:290-296

Morris I, Syrett PJ (1963) The development of nitrate reductase in Chlorella and its repression by ammonium. Arch Mikrobiol 47: $32-41$

Park J, Jin H-F, Lim B-R, Park K-Y, Lee K (2010) Ammonia removal from anaerobic digestion effluent of livestock waste using green alga Scenedesmus sp. Bioresour Technol 101:8649-8657
Pruvost J, Van Vooren G, Cogne G, Legrand J (2009) Investigation of biomass and lipids production with Neochloris oleoabundans in photobioreactor. Bioresour Technol 100:5988-5995

Pulz O, Gross W (2004) Valuable products from biotechnology of microalgae. Appl Microbiol Biotechnol 65:635-648

Redfield AC (1934) On the proportions of organic derivatives in sea water and their relation to the composition of plankton. James Johnstone Memorial Volume. The University Press, In, pp 176-192

Renou S, Givaudan JG, Poulain S, Dirassouyan F, Moulin P (2008) Landfill leachate treatment: review and opportunity. J Haz Mat 150:468-493

Rippka R, Deruelles J, Waterbury JB, Herdman M, Stanier RY (1979) Generic assignments, strain histories and properties of pure cultures of cyanobacteria. J Gen Microbiol 111:1-61

Selvaratnam T, Pegallapati A, Montelya F, Rodriguez G, Nirmalakhandan N, Lammers PJ, van Voorhies W (2015) Feasibility of algal systems for sustainable wastewater treatment. Renew Energy 82:71-76

Shen Y, Yang T, Zhu W, Zhao Y (2017) Wastewater treatment and biofuel production through attached culture of Chlorella vulgaris in a porous substratum biofilm reactor. J Appl Phycol 29:833-841

Spolaore P, Joannis-Cassan C, Duran E, Isambert A (2006) Commercial applications of microalgae. J Biosci Bioeng 101:87-96

Sukenik A, Beardall J, Kromkamp JC, Kopecky J, Masojídek J, Van Bergeijk S, Gabai S, Shaham E, Yamshon A (2009) Photosynthetic performance of outdoor Nannochloropsis mass cultures under a wide range of environmental conditions. Aquat Microb Ecol 56:297-308

Szabó M, Parker K, Guruprasad S, Kuzhiumparambil U, Lilley RM, Tamburic B, Schliep M, Larkum AWD, Schreiber U, Raven JA, Ralph PJ (2014) Photosynthetic acclimation of Nannochloropsis oculata investigated by multi-wavelength chlorophyll fluorescence analysis. Bioresour Technol 167:521-529

Wang L, Min M, Li Y, Chen P, Chen Y, Liu Y, Wang Y, Ruan R (2010) Cultivation of green algae Chlorella sp. in different wastewaters from municipal wastewater treatment plant. Appl Biochem Biotechnol 162:1174-1186

White S, Anandraj A, Bux F (2011) PAM fluorometry as a tool to assess microalgal nutrient stress and monitor cellular neutral lipids. Bioresour Technol 102:1675-1682

Zhang Y, Su H, Zhong Y, Zhang C, Shen Z, Sang W, yan G, Zhou X (2012) The effect of bacterial contamination on the heterotrophic cultivation of Chlorella pyrenoidosa in wastewater from the production of soybean products. Water Res 46:5509-5516. doi:

Publisher's note Springer Nature remains neutral with regard to jurisdictional claims in published maps and institutional affiliations. 